\title{
Banyak Pohon Pembangun pada Graf Barbell
}

\author{
Muklas Maulana ${ }^{a}$, Ni Wayan Switrayni ${ }^{b}$ \\ a Program Studi Matematika, Universitas Mataram, Jl. Majapahit 62, Mataram, 83125, Indonesia. Email: \\ muklas.1.maulana@gmail.com \\ ${ }^{b}$ Program Studi Matematika, Universitas Mataram, J1. Majapahit 62, Mataram, 83125, Indonesia. Email: \\ niwayan.switrayni@unram.ac.id
}

\section{A B S T R A C T}

Graph Theory has many applications in dailylife. One of the topics discussed in graph theory is the number of spanning trees of a graph. In graph theory, a tree is aconnected graph that has no cycle. The number of spanning trees of a connected graph is defined as the number of trees that can be constructed from the graph which passing through all its vertices. In this paper, spanning trees from a barbell graph will be discussed. A Barbell Graph $B(p, n)$ is a graph obtained by connecting $n$-copies of a complete graph $K_{p}$ by a bridge. In this article it is found that the number of spanning trees of barbell graph $B(p, n)$ is equal to $\left(p^{p-2}\right)^{n}$. Some characteristic of spanning trees and barbell graph also will be discussed in this paper.

Keywords: Graph, Barbell Graph, Complete Graph, Spanning Trees.

\section{A B S T R A K}

Teori graf merupakan salah satu bidang ilmu yang memiliki berbagai kegunaan dalam kehidupan sehari-hari. Salah satu topik yang dibahas dalam teori graf yaitu terkait banyak pohon pembangun (Spanning Trees). Pohon (Tree) dalam teori graf merupakan suatu graf terhubung yang tidak memuat cycle. Kemudian banyak pohon pembangun (spanning trees) dari suatu graf terhubung didefinisikan sebagai banyaknya pohon yang dapat dibentuk dari suatu graf yang melewati semua simpul pada graf tersebut. Pada penelitian ini, akan dibahas terkait spanning trees atau pohon pembangun dari graf barbell.Graf Barbell $B(p, n)$ merupakan graf yang diperoleh dengan menghubungkan $n$ buah graf lengkap $K_{p}$ oleh sebuah bridge. Berdasarkan hasil penelitian dari artikel ini diperoleh suatu fakta bahwa graf barbell $B(p, n)$ memiliki spanning trees sebanyak $\left(p^{p-2}\right)^{n}$. Selanjutnya pada artikel ini juga akan dibahas terkait beberapa sifat dari spanning trees dan graf barbell.

Keywords: Graf, Graf Barbell, Graf Lengkap, Spanning Trees Diserahkan: 26-12-2019; Diterima: 31-12-2019; Doi: https://doi.org/10.29303/emj.v1i2.46

* Corresponding author.

Alamat e-mail: muklas.I.maulana@gmail.com 


\section{Pendahuluan}

Graf $G$ adalah pasangan himpunan $(V, E)$ dengan $V$ adalah himpunan tak kosong dan berhingga dari objek-objek yang disebut sebagai simpul dan $E$ adalah himpunan (mungkin kosong) pasangan tak berurutan dari simpul-simpul berbeda di $V$ yang disebut sebagai sisi.

Dalam teori graf, salah satu topik yang menarik untuk dibahas yaitu terkait banyak pohon pembangun (Spanning Trees) dari suatu graf. Banyak pohon pembangun suatu graf menyatakan seberapa banyak pohon yang dapat dibentuk dari suatu graf. Konsep pohon pembangun (spanning trees) suatu graf, dapat diaplikasikan dalam sirkuit elektronik, serta jaringan listrik dan komunikasi.

Berdasarkan penelitian Haghighi dkk pada tahun 2012, telah diperoleh beberapa formula terkait banyak pohon pembangun dari beberapa graf, seperti graf lengkap, graf roda, graf kipas, dan graf sikel. Kemudian pada tahun 2016, Aghasti dkk telah membahas pelabelan graf garis dari graf barbell. Pada penelitian-penelitian tersebut, belum dibahas terkait banyak pohon pembagun dari graf barbell. Oleh karena itu penulis menilai penting untuk membahas banyak pohon pembangun dari graf barbell untuk mengetahui formula dari banyak pohon pembangun suatu graf barbell.

\section{Tinjauan Pustaka}

Sebelum membahas mengenai banyak pohon pembangun suatu graf barbell, terlebih dahulu akan dipaparkan beberapa definisi dan teorema sebagai landasan dalam menulis penelitian ini.

\section{Definisi 2.1 (Wilson, 2010)}

Graf $G$ adalah pasangan himpunan $(V, E)$ dengan $V$ adalah himpunan tak kosong dan berhingga dari objek-objek yang disebut sebagai simpul dan $E$ adalah himpunan (mungkin kosong) pasangan tak berurutan dari simpul-simpul berbeda di $V$ yang disebut sebagai sisi.

\section{Definisi 2.2 (Chartrand, 1986)}

Sisi $e=(u, v)$ dikatakan menghubungkan simpulu dan $v$. Jika $e=(u, v)$ adalah sisi di graf $G$, maka $u$ dan $v$ disebut terhubung langsung (adjacent), $u$ dan $e$ serta $v$ disebut terkait langsung (incident).

\section{Definisi 2.3 (Rosyidah, 2010)}

Graf lengkap adalah graf dengan dua simpul yang berbeda saling berhubungan (adjacent). Graf lengkap dengan $p$ simpul dinyatakan dengan $K_{p}$.

Contoh:

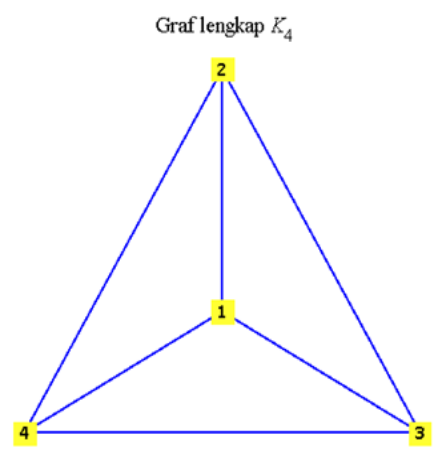

Gambar 1

\section{Definisi 2.4 (Chartrand, 1986)}

Derajat dari simpulv di graf $G$ ditulis dengan $\operatorname{deg}_{G}(v)$, adalah banyaknya sisi di $G$ yang terkait langsung (incident) dengan $v$.

\section{Definisi 2.5 (Agasthi, 2016)}

Graf Barbell $B(p, n)$ merupakan graf yang diperoleh dengan menghubungkan $n$ buah graf lengkap $K_{p}$ oleh sebuah bridge.

Contoh:

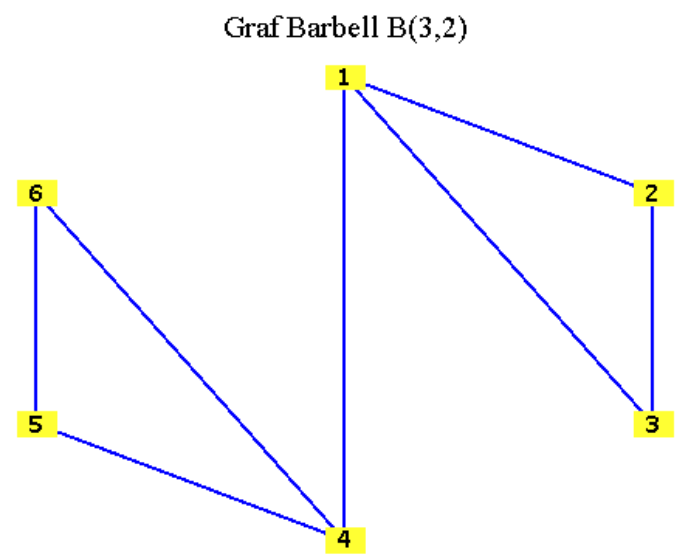

Gambar 2 


\section{Definisi 2.6 (Wilson, 2010)}

Suatu graf dikatakan terhubung jika graf tersebut tidak dapat dinyatakan sebagai gabungan dari beberapa graf.

\section{Definisi 2.7 (Wilson, 2010)}

Sebuah graf terhubung yang tidak memuat cycle disebut dengan pohon (Tree).

\section{Definisi 2.8 (Wilson, 2010)}

Misal $G$ merupakan suatu graf, walk pada $G$ merupakan barisan berhingga dari sisi-sisi yang dinotasikan dengan $v_{0} v_{1}, v_{1} v_{2}, \ldots, v_{m-1} v_{m}$, dengan setiap dua buah sisi berurutan terhubung langsung (adjacent).

\section{Definisi 2.9 (Wilson, 2010)}

Sebuah walk yang semua sisi-sisinya berbeda disebut sebagai trail.

\section{Definisi 2.10 (Wilson, 2010)}

Sebuah trail yang setiap simpulnya berbeda (simpul awal dan akhir boleh sama) disebut sebagai path.

\section{Definisi 2.11 (Harary, 1969)}

Panjang dari suatu path merupakan banyaknya sisi yang terdapat pada path tersebut.

\section{Definisi 2.12 (Harary, 1969)}

Jarak $d(u, v)$ antara simpul $u$ dan $v$ merupakan panjang path terpendek yang menghubungkan $u$ dan $v$. Path $u-v$ terpendek disebut sebagai geodesic.

\section{Definisi 2.13 (Harary, 1969)}

Diameter $\operatorname{diam}(G)$ dari graf terhubung $G$ merupakan panjang dari geodesic yang terpanjang pada graf $G$.

\section{Teorema 2.14(Wilson, 2010)}

Terdapat $n^{n-2}$ pohon berlabel berbeda dengan $n$ simpul.

\section{Bukti:}

Kita memerlukan sebuah korespondensi satu-satu antara himpunan pohon berlabel(bertanda) dengan $n$ simpul dan himpunan barisan $\left(a_{1}, a_{2}, \ldots, a_{n-2}\right)$ dengan $a_{i}$ bilangan bulat yang memenuhi $1 \leq a_{i} \leq$ n.Terdapat barisan tepat $n^{n-2}$ barisan yang memenuhi sifat tersebut. Misalkan $n \geq 3$, karena jika $n=1$ atau $n=2$ terlihat jelas.

Untuk memperoleh korespondensi satu-satu tersebut, misalkan $T$ adalah pohon bertanda dengan orde $n$. Misal $b_{1}$ adalah tanda(label) yang diletakkan pada suatu simpul akhir dan $a_{1}$ merupakan simpul yang adjacent dengan $b_{1}$. Ilustrasi:

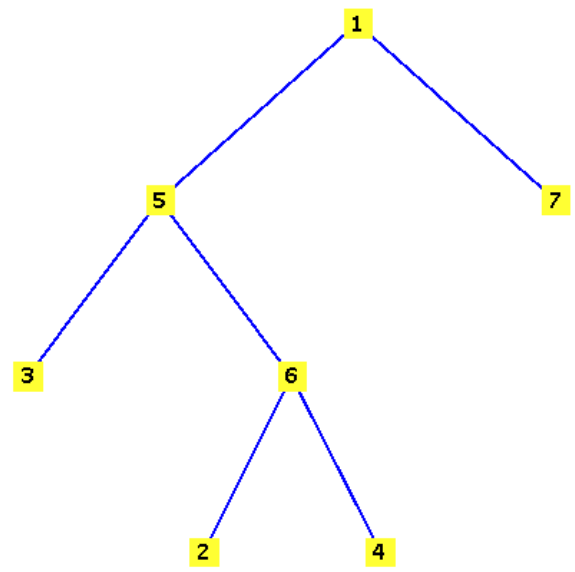

Gambar 3

Berdasarkan gambar $3, b_{1}=2, a_{1}=6$. Kemudian kita hilangkan simpul $b_{1}$ dan sisi yang berincident dengannya sehingga tersisa pohon bertanda berorde $n-1$. Kemudian misal $b_{2}$ merupakan label terkecil diletakkan pada simpul akhir dari pohon yang baru dan $a_{2}$ adalah simpul yang adjacent dengan $b_{2}$. Pada gambar $3, b_{2}=3$ dan $a_{2}=5$. Kemudian simpul $b_{2}$ dihilngkan beserta sisi yang berincident dengannya seperti sebelumnya. Proses ini dilakukan terus sehingga tersisa dua simpul; barisan yang diperlukan menjadi $\quad(6,5,6,5,1)$. Untuk memperoleh korespondensi yang sebaliknya, diambil barisan $\left(a_{1}, a_{2}, \ldots, a_{n-2}\right)$, misal $b_{1}$ adalah bilangan terkecil dari 1 sampai $n$ yang tidak muncul di barisan tersebut, dan meghubungkan $a_{1}$ dan $b_{1}$; sebagai contoh pada $(6,5,6,5,1), a_{1}=6, b_{1}=2$ dan sisi pertama adalah 62 . Kemudian $a_{1}$ dihilangkan dari barisan tersebut dan $b_{1}$ seperti pada proses sebelumnya. Pada contoh ini $a_{2}=5, b_{2}=3$ dan sisi kedua 53, $a_{3}=6, b_{3}=4$ dan sisi yang terbentuk 64 . Proses tersebut dilakukan berulang kali sehingga tersisa dua simpul yaitu 1 dan 7. Perhatikan bahwa jika kita memulai dari sebarang pohon bertanda, kemudian mencari barisan yang berkorespondensi dengan pohon tersebut, akan diperoleh kembali pohon awal tersebut. Sehingga diperoleh korespondensi satu-satu yang diinginkan. 
Akibat 2.15(Wilson, 2010)

Banyak pohon pembangun dari $K_{p}$ adalah $p^{p-2}$.

Bukti:

Graf $K_{p}$ merupakan graf terhubung dengan $p$ simpul. Setiap simpul pada $K_{p}$ memberikan pohon-pohon pembangun yang unik. Sehingga berdasarkan teorema 2.7 terdapat $p^{p-2}$ pohon berbeda dari graf $K_{p}$.

Teorema 2.16(Wilson, 2010)

Misalkan $G$ merupakan graf terhubung sederhana dengan himpunan simpul $\left\{v_{1}, v_{2}, \ldots, v_{n}\right\}$, dan misalkan $\boldsymbol{M}=\left(m_{i j}\right)$ merupakan matriks berukuran $n \times n$ dengan $m_{i i}=\operatorname{deg}\left(v_{i}\right), m_{i j}=-1$ jika $v_{i}$ dan $v_{j}$ adjacent, dan $m_{i j}=0$ untuk lainnya. Maka banyak pohon pembangun dari $G$ sama dengan kofaktor dari sebarang element di $\boldsymbol{M}$.

Bukti:

Karena $M=A A^{t}$ dengan $A$ merupakan matriks incidence maka diperoleh $M_{0}=A_{0} A_{0}^{t}$, dengan $M_{0}$ merupakan matriks yang diperoleh dengan menghilangkan sebarang baris dan kolom dari $M$. Sehingga diperoleh

$$
\operatorname{det}\left(M_{0}\right)=\sum_{S}\left(\operatorname{det} A_{0}[S]\right)\left(\operatorname{det} A_{0}^{t}[S]\right),
$$

Dengan $S$ merupakan range dari semua elemen ke $(p-1)$ dari subset $\{1,2, \ldots, q\}$ (atau secara ekuivalen, dari $(p-1)$-elemen subset dari himpunan sisi di $G$ ). Karena secara umum $K^{t}[S]=$ $K[S]^{t}$ dengan $K$ merupakan matriks adjacent, maka persamaan (1) menjadi

$\operatorname{det}\left(M_{0}\right)=\sum_{S}\left(\operatorname{det} A_{0}[S]\right)^{2}$

Karena $\operatorname{det}\left(A_{0}[S]\right)= \pm 1$ jika $S$ membentuk himpunan sisi-sisi spanning trees dari $G$, dan 0 jika sebaliknya, maka bentuk yang berindeks $S$ dari jumlahan pada persamaan (2) bernilai 1 jika $S$ membentuk himpunan sisi-sisi spanning trees dari $G$ dan 0 jika sebaliknya. Oleh karena itu jumlahan pada persamaan (2) sama dengan $\kappa(G)$.

\section{Hasil dan Pembahasan}

Berdasarkan bagian sebelumnya, telah dijelaskan bahwa graf lengkap $K_{p}$ memiliki pohon pembangun sebanyak $p^{p-2}$. Pada bagian ini akan dibahas mengenai banyak pohon pembangun dari graf barbell $B(p, n)$.

\section{Graf barbell $B(3,2)$}

Graf barbell $B(3,2)$ merupakan graf barbell yang dibentuk dengan menghubungkan dua buah graf lengkap $K_{3}$ melalui sebuah bridge. Berikut adalah ilustrasi dari graf barbell $B(3,2)$ :

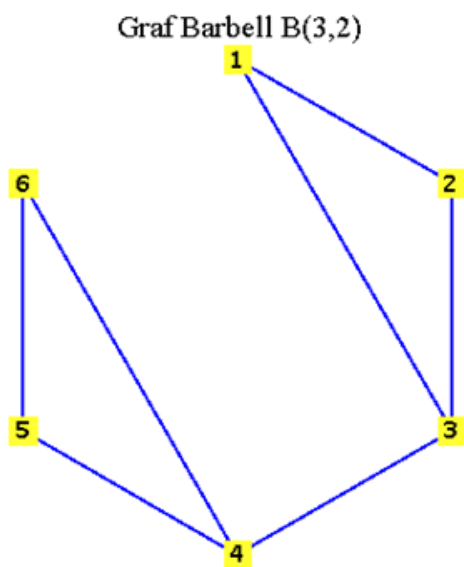

Gambar 4

berdasarkan ilustrasi tersebut, dibentuk matriks $\boldsymbol{M}$ sebagai berikut:

$$
M=\left[\begin{array}{cccccc}
2 & -1 & -1 & 0 & 0 & 0 \\
-1 & 2 & -1 & 0 & 0 & 0 \\
-1 & -1 & 3 & -1 & 0 & 0 \\
0 & 0 & -1 & 3 & -1 & -1 \\
0 & 0 & 0 & -1 & 2 & -1 \\
0 & 0 & 0 & -1 & -1 & 2
\end{array}\right]
$$

Yang nilai dari sebarang kofaktornya adalah 9. Selanjutnya akan dihitung banyak pohon pembangun dari graf barbell $B(4,2)$.

\section{Graf barbell $B(4,2)$}

Graf barbell $B(4,2)$ merupakan graf barbell yang dibentuk dengan menghubungkan dua buah graf $K_{4}$ dengan sebuah bridge. Ilustrasi dari graf barbell $B(4,2)$ adalah sebagai berikut: 


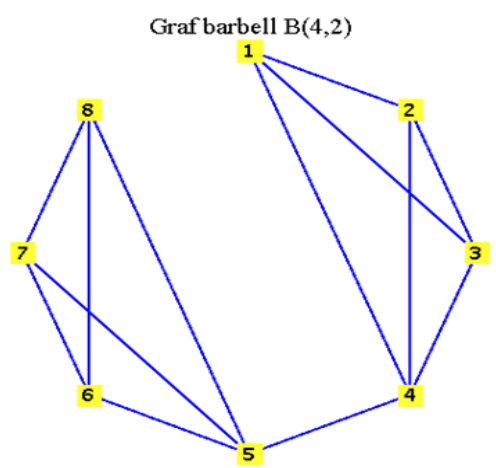

Gambar 5

berdasarkan ilustrasi di atas, dibentuk matriks $M$ sebagai berikut:

$$
M=\left[\begin{array}{cccccccc}
3 & -1 & -1 & -1 & 0 & 0 & 0 & 0 \\
-1 & 3 & -1 & -1 & 0 & 0 & 0 & 0 \\
-1 & -1 & 3 & -1 & 0 & 0 & 0 & 0 \\
-1 & -1 & -1 & 4 & -1 & 0 & 0 & 0 \\
0 & 0 & 0 & -1 & 4 & -1 & -1 & -1 \\
0 & 0 & 0 & 0 & -1 & 3 & -1 & -1 \\
0 & 0 & 0 & 0 & -1 & -1 & 3 & -1 \\
0 & 0 & 0 & 0 & -1 & -1 & -1 & 3
\end{array}\right]
$$

Yang nilai dari sebarang kofaktornya adalah 256. Sehingga banyak pohon pembangun dari graf barbell $B(4,2)$ adalah 256. Selanjutnya akan dibahas mengenai banyak pohon pembangun dari graf barbell $B(5,2)$.

\section{Graf Barbell $B(5,2)$}

Graf barbell $B(5,2)$ merupakan graf barbell yang dibentuk dengan menghubungkan dua buah graf $K_{5}$ dengan sebuah bridge. Ilustrasi dari graf barbell $B(5,2)$ adalah sebagai berikut:

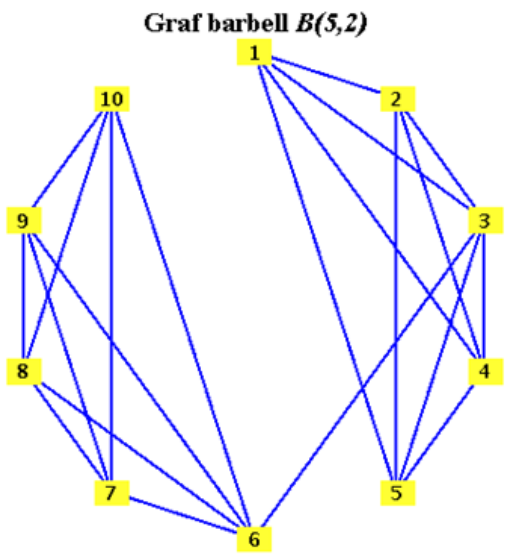

Gambar 6

Berdasarkan ilustrasi di atas, dibentuk matriks $M$ sebagai berikut:

$$
M=\left[\begin{array}{cccccccccc}
4 & -1 & -1 & -1 & -1 & 0 & 0 & 0 & 0 & 0 \\
-1 & 4 & -1 & -1 & -1 & 0 & 0 & 0 & 0 & 0 \\
-1 & -1 & 5 & -1 & -1 & -1 & 0 & 0 & 0 & 0 \\
-1 & -1 & -1 & 4 & -1 & 0 & 0 & 0 & 0 & 0 \\
-1 & -1 & -1 & -1 & 4 & 0 & 0 & 0 & 0 & 0 \\
0 & 0 & -1 & 0 & 0 & 5 & -1 & -1 & -1 & -1 \\
0 & 0 & 0 & 0 & 0 & -1 & 4 & -1 & -1 & -1 \\
0 & 0 & 0 & 0 & 0 & -1 & -1 & 4 & -1 & -1 \\
0 & 0 & 0 & 0 & 0 & -1 & -1 & -1 & 4 & -1 \\
0 & 0 & 0 & 0 & 0 & -1 & -1 & -1 & -1 & 4
\end{array}\right]
$$

Yang nilai dari sebarang kofaktornya adalah 15.625. oleh karena itu diperoleh fakta bahwa banyak pohon pembangun dari graf barbell $B(5,2)$ adalah 15.625. selanjutnya akan dikemukakan sebuah teorema terkait banyak pohon pembangun dari graf barbell $B(p, n)$.

\section{Teorema 3.1}

Misalkan $G_{1}, G_{2}, \ldots, G_{k}$ adalah graf terhubung dengan masing-masing banyak pohon pembangun dari $G_{i}$ adalah $n_{i}, i \in\{1,2, \ldots, k\}$. Banyak pohon pembangun dari graf $G$ yang dibentuk dengan menghubungkan graf $G_{1}, G_{2}, \ldots, G_{k}$ menggunakan tepat satu bridge yaitu sebanyak $\prod_{i=1}^{k} n_{i}$

\section{Bukti:}

Untuk $k=2$, graf $G=G_{1}-G_{2}$ yang terbentuk merupakan sebuah graf yang diperoleh dengan menghubungkan dua buah graf $G_{1}$ dan $G_{2}$ menggunakan sebuah bridge. Misalkan graf $G_{2}$ memiliki banyak pohon pembangun sebanyak $n_{2}$ dan $G_{1}$ memiliki pohon pembangun sebanyak $n_{1}$. Pohon pembangun dari $G$ dibentuk dengan menghubungkan pohon pembangun di $G_{1}$ dengan pohon pembangun di $G_{2}$ melalui sebuah bridge. Misalkan diambil sebarang pohon pembangun di $G_{1}$ yaitu $T_{1}$, maka terdapat $n_{2}$ buah pohon pembangun pada $G$ yang dimulai dari $T_{1}$. Karena terdapat $n_{1}$ pohon pembangun di $G_{1}$, maka dengan mengulangi langkah serupa diperoleh jumlah pohon pembangun dari $G$ adalah $n_{1} \times n_{2}$.

Andaikan benar untuk $k=m$, maka harus ditunjukkan benar untuk $k=m+1$. Perhatikan bahwa graf $G_{a}=G_{1}-G_{2}-\cdots-G_{m}-G_{m+1}$ dibentuk dengan menghubungkan $G_{b}=G_{1}-G_{2}-$ $\cdots-G_{m}$ dengan $G_{m+1}$. Misalkan pohon pembangun dari $G_{b}$ sebanyak $\prod_{i=1}^{m} n_{i}$, dan pohon pembangun dari $G_{m+1}$ sebanyak $n_{m+1}$. Maka dengan argumen yang serupa seperti pada $k=2$, dengan mengambil sebarang pohon $T_{1}$ di $G_{b}$ diperoleh $n_{m+1}$ pohon pembangun pada $G_{a}$ yang dimulai dari $T_{1}$. Karena terdapat $\prod_{i=1}^{m} n_{i}$ pohon pembangun di $G_{b}$, maka diperoleh banyaknya pohon pembangun dari $G_{a}=$ $G_{1}-G_{2}-\cdots-G_{m}-G_{m+1}=\prod_{i=1}^{m} n_{i} \times n_{m+1}=$ $\prod_{i}^{m+1} n_{i}$. 


\section{Akibat 3.2}

Banyaknya pohon pembangun dari graf barbell $B(p, n)$ adalah sebanyak $\left(p^{p-2}\right)^{n}$.

\section{Bukti:}

Berdasarkan akibat 2.15 diperoleh fakta bahwa banyak pohon pembangun dari $K_{p}$ adalah $\left(p^{p-2}\right)$. Graf $B(p, n)$ merupakan graf yang diperoleh dengan menghubungkan $n$ buah graf $K_{p}$ melalui sebuah bridge. Dengan menggunakan teorema 3.1 maka banyaknya pohon pembangun pada $B(p, n)$ sebanyak $\left(p^{p-2}\right)^{n}$

\section{Teorema 3.3}

Misalkan $B(p, n)$ merupakan graf barbell yang diperoleh dengan menghubungan $n$ buah graf $K_{p}$ dengan sebuah bridge, maka berlaku:

$\operatorname{diam}(B(p, n))=2 n-1$

Bukti:

Graf $B(p, n)$ dibentuk dengan menghubungkan $n$ buah graf $K_{p}$ menggunakan sebuah bridge. Banyak bridge yang digunakan untuk menghubungkan $n$ buah graf $K_{p}$ adalah $n-1$. Karena $\operatorname{diam}\left(K_{p}\right)=1$, maka untuk $n=2$, ketika dua buah graf $K_{p}$ dihubungkan dengan sebuah bridge maka diameter total dari graf $B(p, 2)$ yang terbentuk adalah $1+1+$ $1=2(2)-1=3$. Andaikan benar untuk $n=k$, maka $\operatorname{diam}(B(p, k))=2 k-1$. Perhatikan bahwa ketika $n=k+1, B(p, k+1)$ merupakan graf yang dibentuk dengan menghubungkan graf barbell $B(p, k)$ dengan sebuah graf $K_{p}$ melalui sebuah bridge. Karena $\operatorname{diam}(B(p, k))=2 k-1 \quad$ dan $\operatorname{diam}\left(K_{p}\right)=1$, maka diperoleh:

$$
\begin{gathered}
\operatorname{diam}(B(p, k+1)=(2 k-1)+1+1 \\
=2(k+1)-1
\end{gathered}
$$

Oleh karena itu terbukti bahwa $\operatorname{diam}(B(p, n)=$ $2 n-1$.

\section{Ucapan Terima Kasih}

Dalam kesempatan ini, penulis ingin menyampaikan ucapan terima kasih kepada:

1. Tuhan Yang Maha Esa yang selalu memberikan rahmat dan karunia-Nya.

2. Kedua orang tua yang selalu memberikan dukungan.

3. Bapak/Ibu dosen pembimbin atas kesediannya meluangkan waktu dalam memberikan bimbingan dan arahan terkait penelitian ini.

\section{DAFTAR PUSTAKA}

Agasthi, P., Parvathi, N., \& Thirusangu, K . (2016). On some Labelling of Barbell Graph. Global Journal of Pure and Applied Mathematics, 12(1), 273-280.

Chartrand, Gary dan Lesniak, Linda. (1986). Graphs and Digraphs Second Edition. United States of America: a Division of Wadsworth.Inc.

Haghighi, M.S., \& Bibak, K. (2012). The Number of Spanning Trees in some Classes of Graphs. Rocky Mountain Journal of Mathematics, 42(4), 11831195.

Harary, F. (1969). Graph Theory. United States of America: Addison-Wesley Publishing Company.

Rosyidah, H. (2010). Grup Automorfisme dari Graph Lengkap dan Graph Sikel (Doctoral dissertation, Universitas Islam Negeri Maulana Malik Ibrahim).

Wilson, R.J.(2010). Introduction to Graph Theory Fifth Edition. United Kingdom: Pearson Education Ltd. 